\title{
Transection Type, Vesico-Vaginal Fistula Surgery
}

\author{
Mamadou II. Barry ${ }^{1,2 *}$, Ibrahima Sory Diallo', Mamadou Bissiriou Bah 1,2, Demba Cisse1,2, \\ Thierno Mamadou Oury Diallo1,2, Mamadou Diawo Bah",2, Lahoumbo Ricardo Gnammi1, \\ Thierno Oumar Diallo', Kindy Diallo3, Daouda Kante1,2, Ibrahima Bah"1,2, Karamoko Bano Sow ${ }^{1,2}$, \\ Abdoulaye Bobo Diallo, , , Oumar Raphiou Bah ${ }^{1,2}$, Sékou Guirassy,2, Mamadou Bobo Diallo1,2 \\ ${ }^{1}$ Urology Andrology Department of Ignace-Deen Hospital, HUC of Conakry, Conakry, Guinea \\ ${ }^{2}$ Gamal Abdel Nasser University, Conakry, Guinea \\ ${ }^{3}$ Labé Regional Hospital, Urology Unity, Conakry, Guinea \\ Email: barry2gn@yahoo.fr
}

How to cite this paper: Barry, M.II., Diallo, I.S., Bah, M.B., Cisse, D., Diallo, T.M.O., Bah, M.D., Gnammi, L.R., Diallo, T.O., Diallo, K., Kante, D., Bah, I., Sow, K.B., Diallo, A.B., Bah, O.R., Guirassy, S. and Diallo, M.B. (2020) Transection Type, Vesico-Vaginal Fistula Surgery. Open Journal of Urology, 10, 263-274.

https://doi.org/10.4236/oju.2020.1011031

Received: May 26, 2020

Accepted: October 24, 2020

Published: October 27, 2020

Copyright $\odot 2020$ by author(s) and Scientific Research Publishing Inc. This work is licensed under the Creative Commons Attribution International License (CC BY 4.0).

http://creativecommons.org/licenses/by/4.0/ (c) (i) Open Access

\begin{abstract}
The objective of the study was to report the results of the surgery of the Vesico-vaginal fistula (VVF) transection types at CHU Conakry. Methods: This was a prospective descriptive study that focused on 64 patients operated for VVF transection type at the Urology department of CHU Conakry between January 2013 and December 2015. Four types of transection were defined according to the state of the urethra and vagina, the size of the fistula, the peri-fistulous tissue and associated lesions. The variables studied were the proportion of transection, age, the type of transection, the number of previous cures, the operative technique, the complications and the results after a follow-up of 3 months. Results: Transection accounted for $47.05 \%$ of the obstetric fistulas. The average age was 25.18 years old (14-43 years old). This was a Type I transection (11 cases), type II (27 cases), type III (19 cases) and type IV (7 cases). The surgical approach was vaginal in 64 cases. Fistulorraphy with a confection of a new cervix and cervico-urethral anastomosis was conducted in 19 patients, combined with bladder flap urethroplasty (30 patients) or vaginal flap (15 others). We recorded healing in 37 cases. Conclusion: Transection type VVF is a severe VVF. The preferential surgical approach was vaginal. Technical difficulties were related to associate lesions and the continence system affected.
\end{abstract}

\section{Keywords}

Vesico-Vaginal Fistula, Transection, Surgery

\section{Introduction}

In developing countries, vesico-vaginal fistulas are secondary to an ischaemic le- 
sion on fetopelvic dystocia resulting from a long delay between the onset of labour and access to a caesarean section [1] [2] [3]. They are public health problems in countries with low medical services and where urgent obstetrics cares are insufficient [4] [5]. The WHO estimated between 2 and 3.5 million women victims of obstetric fistula in the world, mainly in Africa [5].

The transections types vesico-vaginal fistulas are severe obstetric fistula due to their extensions, associated lesions and the damage of the continence system [3] [4]. Several classifications of the obstetric fistula were reported in the literature but few authors were interested in transection only.

The classification of Waaldijk [6] describes three types of fistulas:

- Type I: Fistulas do not involve the urethral closing mechanism;

- Type II: Fistulas involve the urethral closing mechanism. It has divided the type II in type IIA without urethral damage, type IIB with urethral damage and subdivided the type IIB in type IIB(a) without circumferential defect IIB (b) with circumferential defect;

- Type III: Ureters and other fistulas.

Falandry's classification [7] takes into consideration the seat of the fistula, the sclero-inflammatory reshuffle and the sphincterial damage. It divides the obstetric fistulas into three groups:

- Group I: Simple fistulas, representing less than $15 \%$ of cases. The fistulous orifice is distant from the urethra or the cervix whatever its size. The tissues are flexible and the prognosis is excellent if only the provided postoperative care is satisfactory;

- Group II: Fistulas representing more than $50 \%$ of cases. They are more or less complex by the extent or by the damage of the Sphincterial device. The sclerosis of the tissues makes the exposure more or less difficult. The prognosis is good, but often at the price of several interventions with sometimes complex techniques (plasty, grafts, artifices) to obtain a seal and continence;

- Group III: About 30\% of cases. These are true extended tissue destruction towards the genital device, urinary and sometimes the ano-rectal sector within scarf tissues whose surgical exposure is difficult, sometimes at the price of incisions that consume time and blood reserves. Some are described as "impossible" beyond the usual surgical techniques. The transsection would correspond to the type II(B) of Waaldijk or Group III of Falandry, that means a fistula with pure cervix disinsertion or cervico-urethral associated with a more or less extended destruction of the urethra. The tissue destruction concerns the posterior wall but also the anterior wall of the bladder, the cervix on all its conference. The urethra is sometimes cut nearest to the cervix and in this case it is normally usable. More often, the urethra is partially destroyed in its proximal part with a closed posterior orifice. The lower edge of the symphysis is no longer covered by a vaginal neo-epithelium. Sclerosis and loss of substance are often major, making the approach and the dissection extremely difficult. At the ultimate stage, the vagina is represented only 
by a sclerous parade in the background of which there is a vesical stump. The associated rectal damages are most often large decay interesting the Sphincter.

All transsection does not come up with such dramatic lesions. Some concern only the cervix with a fistula overflowing a little on the trigone, an urethra fairly well maintained with a moderate sclerosis. Nevertheless, they have in common a circular damage at least at the level of the cervix, where the lower edge of the pubis is nacked [7]. All these anatomic clinical varieties require classification and require surgical experience in the repair of fistulas as in addition to the difficulties of access, the vesical neck to rebuild we can be brought to achieve uretroplasty from bladder or vaginal tissue in order to restore anatomy and urinary continent.

\section{Methodology}

It was a prospective descriptive study of three years duration, ranging from January $1^{\text {st }}, 2013$ to December 31, 2015. All the women operated of VVF transection type during the study period and having a complete medical file with a follow-up of at least 3 months were included.

A sample of 64 patients was the subject of this study. The study variables were: the proportion of transection compared to other obstetric fistula, age, reasons for consultation, the number of previous cures, the type of transection, the operation technique, the preoperative and postoperative complications. The review under the valve in the operating block has made it possible to highlight four types of transsection that have been defined according to the state of the urethra and vagina, the size of the fistula, the nature of the peri-fistuluous tissue and associated damages. These were:

- Type I Transection (Figure 1): the urethra is being sectioned close to the cervix. The destruction of the proximal urethra was less than or equal to $1 \mathrm{~cm}$. The fistulous orifice and the vagina were flexible.

- Type II Transection (Figure 2): The fistula the interest is in the Trigono-Cervico-Urerthral region with partial destruction of the urethra that was between 1 and $2 \mathrm{~cm}$. There was a loss of substance and a vaginal flange.

- Type III Transection (Figure 3): In this type, vaginal sclerosis and the loss of substance were major, sometimes making the vagina unpermeable. The remaining urethra was less than a centimeter. The surgery pathway and dissection were difficult.

- Type IV Transection: When the transection was associated with either a vesico-uterine fistula (VUF) or an uretero-vagina fistula (UVF) or a recto-vaginal fistula (RVF).

We have retained the patients in accordance with this classification adopted in our service for transections. After a follow-up of at least three months, the results were judged:

- Good: when the fistula was closed and the urination was restored.

- Poor: When urinal incontinence is persisting despite the closure of the fistula.

- Failure: When the fistula was not or incompletely closed. 


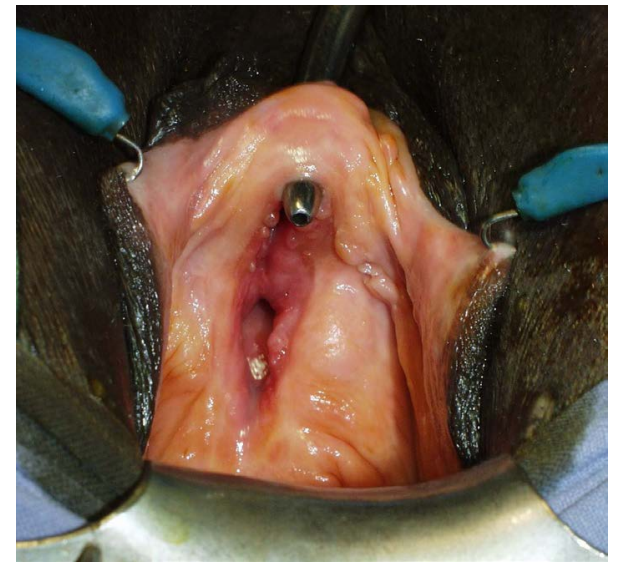

Figure 1. Type I complete transection (urethra section close to the cervix, the fistulous orifice and the vagina remain flexible).

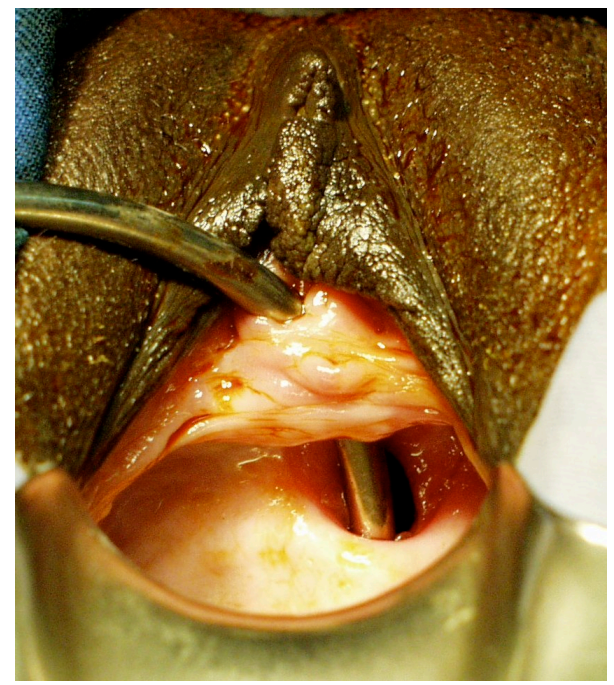

Figure 2. Type II Transection (Loss of substance and a vaginal flange, $2 \mathrm{~cm}$ of urethra remaining).

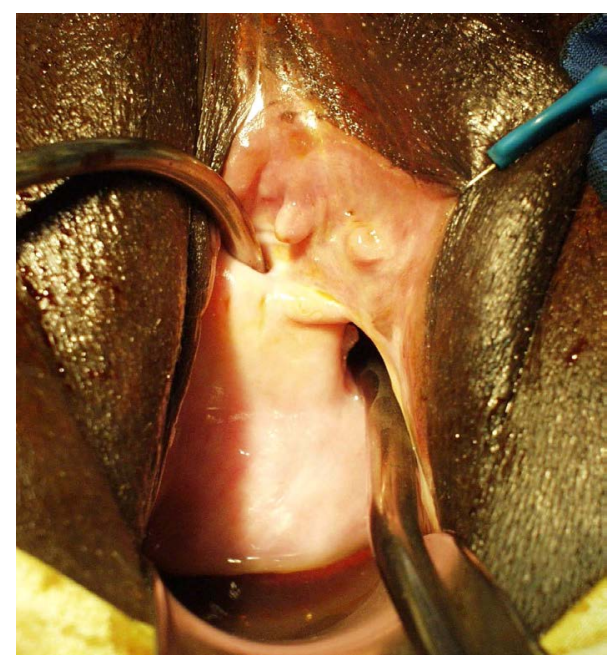

Figure 3. Type III Transection (complete destruction of the urethra, large vaginal bride, difficult approach and dissection). 
These results were reviewed according to the type of transection, the number of previous cures, the status of the vagina and the operation technique.

\section{Results}

During the study period, we raised 64 cases of VVF transection type representing $47.05 \%$ of obstetric fistula. The recto-vaginal fistula were all obstetrics and associated with a VVF (Table 1).

Table 1. Socio-demographic and clinical characteristics of the patients.

\begin{tabular}{|c|c|c|}
\hline Socio-demographic and clinical characteristics & effectif & $\%$ \\
\hline \multicolumn{3}{|l|}{ Age $^{*}$} \\
\hline $14-23$ & 32 & 50 \\
\hline $24-33$ & 21 & 32.80 \\
\hline $34-43$ & 11 & 17.20 \\
\hline \multicolumn{3}{|l|}{ Profession } \\
\hline House wife & 59 & 92.20 \\
\hline Taylor & 3 & 4.68 \\
\hline Trader & 1 & 1.56 \\
\hline Student & 1 & 1.56 \\
\hline \multicolumn{3}{|l|}{ gravidity } \\
\hline Primiparous & 32 & 50 \\
\hline Pauciparous & 15 & 23.44 \\
\hline Multiparous & 17 & 26.56 \\
\hline \multicolumn{3}{|l|}{ Place of delivery } \\
\hline Hospital & 34 & 53.12 \\
\hline Home & 27 & 42.20 \\
\hline Health center & 3 & 4.68 \\
\hline \multicolumn{3}{|l|}{ Route of delivery } \\
\hline Vaginal delivery & 48 & 75 \\
\hline Caesarean section & 16 & 25 \\
\hline \multicolumn{3}{|l|}{ Reason for consultation } \\
\hline Urine leaking from the vagina & 64 & 100 \\
\hline Loss of feces from the vagina & 4 & 6.25 \\
\hline Cyclic hematuria & 1 & 1.56 \\
\hline \multicolumn{3}{|l|}{ Nomber of previous cure ${ }^{* *}$} \\
\hline once & 15 & 23.43 \\
\hline Two times & 9 & 14.06 \\
\hline Three times & 4 & 6.25 \\
\hline
\end{tabular}

*The average age of patients at the moment of the diagnosis was 25 years with the extrem of 14 and 43 years. ${ }^{* *}$ More than half $(\mathrm{n}=36)$ have never been operated of the fistula. 
The average age of the patients at the time of the fistula was 25.18 years old with extremes of 14 and 43 years. Half of the patients ( 32 cases) had an age between 14 and 23 years old. The profession was that of housewives in $92.1 \%(\mathrm{n}=$ 59 ) and one patient had a primary level of education.

Vaginal urine leak was noted in all patients (64 cases) and was associated with loss of feces through the vulva in 4 cases and a cyclic hematuria in one case.

Vaginal delivery was reported from 48 patients (75\%) and by Caesarean from 16 patients (25\%). After dystocic work, the delivery was held at the hospital for 34 patients (53.1\%), at home for 27 patients (42.2\%), at the health center for 3 patients. The fistula occurred in a primiparous in the half of cases $(n=32)$, in a pauciparous within $23.43 \%$ of cases $(n=15)$ and in a multiparous in $26.56 \%$ of cases ( $\mathrm{n}=17$ cases).

In the history of the fistula cure, the first cure has been reported in $15 \mathrm{pa}$ tients, two cures in 9 patients and three cures in 4 patients. Thirty six patients had no previous cure.

At the examination under valve, the urethra was partially destroyed in 31 patients, totally in 15 patients and intact in 18 patients. It was also permeable in 41 patients and blind in 8 patients. The vagina was flexible in 23 patients, sclerotic in 37 patients and unpermeable in 4 patients.

The transection was associated with a RVF in 4 patients, a UVF in 2 patients and a VUF in a patient.

The types II and III of the transection were the most represented with $42.2 \%$ and $29.7 \%$ respectively. Types I and IV were found in $17.2 \%$ and $10.9 \%$ of cases respectively.

We used a spinal anesthesia in 58 patients (90.6\%), a general anesthesia in 3 patients (4.7\%) and an addition of a spinal anesthesia in 3 other cases.

The surgical approach was vaginal with 64 patients and mixed with 2 patients (3\%) for the cure of a vesico-uterine fistula and an uretero-vesical reimplantation.

Fistulorraphy with a confection of a new-vervix and cervico-urethral anastomosis was the basic technique in 19 patients, combined with bladder flap urethroplasty in 30 patients or vaginal flap in 15 others. Among the associated gestures, a large bilateral or later posterior episiotomy had been required 39 times, the urethral trocardization 8 times, the rectal fistulorraphy 5 times, the uretero-vesical reimplantation 2 times. The Vesico-uterine fistulorraphy and the replacement of a flap was needed once in each case.

The operating suites were simple in $84.4 \%(\mathrm{n}=54)$. Among ten patients (15.6\%) we noted complications such as vomiting + fever (4 times), lumbar pain + vomiting ( 2 times), headache + fever (2 times), ileus ( 1 time) and calcification on hair (1 time).

For the 64 patients, we made 96 surgical procedures, giving a repeated surgery survey of $33 \%$ of cases.

The vesical drainage was carried out by urethral catheterism and lasted 14 days for 19 patients and 21 days for 45 patients according to whether the transection was isolated or associated with urethroplasty. 
The results of this transection surgery were deemed good in 37 patients (58\%), failure in 21 patients and poor in 6 patients.

The comparative analysis of the overall results compared to the type of transection has raised that the best results were obtained with the I and II types (Table 2).

Out of 36 patients who had no previous surgery, 22 were cured giving a success rate of $61.11 \%$. The failure rate increased from $25 \%$ when there was no restorative surgery and to $50 \%$ when there were 3 times of surgical cure (Table 3 ).

According to the status of the vagina, all the failure cases were associated with a sclerotic or unpermeable vagina (Table 4).

According to the operative technique, the fistulorraphy associated with urethroplasty with vaginal flap grouped the highest failure rate (Table 5).

Table 2. Distribution of the surgery results compared to the types of transection.

\begin{tabular}{ccccc}
\hline \multirow{2}{*}{ Types of transsection } & \multicolumn{3}{c}{ Results } \\
\cline { 2 - 4 } & Good & Poor & Failure & TOTAL \\
\hline Type I & $11(100 \%)$ & - & - & $11(100 \%)$ \\
Type II & $22(81 \%)$ & - & $5(19 \%)$ & $27(100 \%)$ \\
Type III & - & $6(32 \%)$ & $13(68 \%)$ & $19(100 \%)$ \\
Type IV & $4(57,1 \%)$ & - & $3(42.9 \%)$ & $7(100 \%)$ \\
\hline
\end{tabular}

Table 3. Distribution of the surgery results compared to the number of previous cures.

\begin{tabular}{ccccc}
\hline \multirow{2}{*}{$\begin{array}{c}\text { Number of } \\
\text { previous cures }\end{array}$} & Good & Poor & Failure & TOTAL \\
\cline { 2 - 4 } & $27(75 \%)$ & 0 & $9(25 \%)$ & $36(100 \%)$ \\
$\mathbf{0}$ & $8(53 \%)$ & $3(20 \%)$ & $4(27 \%)$ & $15(100 \%)$ \\
$\mathbf{1}$ & $3(33.3 \%)$ & $2(22.2 \%)$ & $4(44.4 \%)$ & $9(100 \%)$ \\
3 & $1(25 \%)$ & $1(25 \%)$ & $2(50 \%)$ & $4(100 \%)$ \\
\hline
\end{tabular}

Table 4. Distribution of the surgery results compared to the state of the vagina.

\begin{tabular}{ccccc}
\hline \multirow{2}{*}{ State of the Vagina } & \multicolumn{4}{c}{ Results } \\
\cline { 2 - 5 } & Good & Poor & Failure & TOTAL \\
\hline Flexible/soft & $21(91.3 \%)$ & $2(8.7 \%)$ & - & $23(100 \%)$ \\
Sclerotic & $16(43 \%)$ & $4(11 \%)$ & $17(46 \%)$ & $37(100 \%)$ \\
Waterproof/impermeable & - & - & $4(100 \%)$ & $4(100 \%)$ \\
\hline
\end{tabular}

Table 5. Distribution of the surgery results compared to the operating techniques.

\begin{tabular}{|c|c|c|c|c|}
\hline Operating techniques & Good & Poor & Failure & Total \\
\hline Fistulorraphy + urethra in vagina & - & $6(40 \%)$ & $9(60 \%)$ & $15(100 \%)$ \\
\hline Fistulorraphy + urethra in bladder & $21(70 \%)$ & - & $9(30 \%)$ & $30(100 \%)$ \\
\hline $\begin{array}{l}\text { Fistulorraphy }+ \text { neo-neck }+ \\
\text { cervico-urethral anastomosis }\end{array}$ & $16(84.2 \%)$ & - & $3(15.8 \%)$ & $19(100 \%)$ \\
\hline
\end{tabular}




\section{Discussion}

Between January 2013 and December 2015, we raised 64 cases of VVF transection type, representing $47.05 \%$ of all obstetric fistulas. In 1995, Guirassy et al. [8] reported that complex fistulas grouped $64 \%$ of cases. Diallo et al. [9] in a study of support of obstetric fistula realized in 3 sites out of our service reported that complex fistulas were $66 \%$ of cases. In a series of 1050 patients from Benchekroun et al. [10], Type I and Type II, corresponding to the transection accounted for $30 \%$ and $22 \%$ of which cases.

The average age of our patients was 25, 18 years with extremes of 14 and 43 years. Ruminjo et al. [11] As well as Frajzyungier et al. [12] reported an average age of 25-year. The young age participates in the foeto-maternal disproportion, responsible for the occurrence of the obstetric fistula [3]. Several authors [4] [10] [13] are unanimous on the occurrence of the fistula in young sexual active patients.

The choice of the surgical approach is not univocal [14] [15] [16]. Fistula may be approached either by vaginal or by trans-vesical or transperitoneal-vesical [15]. Bodner-Adler et al. [17] in a meta-analysis had reported the laparoscopic lane and robot assisted in $15 \%$ of cases with an estimated success rate at $98.87 \%$ of cases. Their choice is based on the complacency of the vagina, the seat of the fistula and associated lesions. It requires a good preoperative assessment, which is based on a vaginal examination carefully made, an assessment of the state of the high urinary device and the flexibility of the tissues. The vaginal path was our main surgery pathway.

Kambou et al. [18] used the vaginal chirurgical approach in $61.4 \%$ of cases. For Moudouni et al. [15], it was used in 70\% of cases.

The vaginal chirurgical approach for us seems to be the best for transections because it gives an operating comfort, direct access to the lesions of the bladder and the urethra. It also allows the tissue interposition and simultaneous surgical approach of an associated RVF. This simultaneous surgical approach was made in the 4 cases of RVF associated with success in half of cases. For Gueye et al. [14], almost all types of vesico-vaginal fistulas can be repaired vaginal surgical approach. There are technical ways to expand the vaginal path:

- The Schuckhar side episiotomy

- The posterior episiotomy of the picot-Couvelaire

- Disinsertion of the anterior face of the bladder to the pubis.

A large bilateral or posterior episiotomy was used in 39 patients and the disinsertion of the anterior face of bladder in all patients.

However the vaginal surgical approach, has a disadvantage, that of not allowing the identification of the ureters except in the large fistula where all the vesical floor is visible.

High chirurgical track or transperitoneal-vesical route is indicated in the high vesico-vaginal fistula or in case of associated lesion such as a vesico-uterine fistula or an uretero-vaginal fistula [10] [14] [16]. In our series, it was associated 
with the vaginal surgical approach in 2 cases.

The simplest technique for repairing VVF is to split and sew separately from the two planes (vesical and vaginal) after reviving the embankment [16]. But this technique that is of great simplicity and low morbidity is not easy in transections. The principle of surgical treatment in our series was fistulorraphy with a confection of a new cervix and cervico-urethral anastomosis in all patients. Urethroplasty was associated with fistulorraphy in 45 patients.

Postoperative vesical drainage was carried out by a urethral probe for several authors [14] [15] [19]. For the blinder reported by MOUDOUNI et al. [15], urine is used to drain by a urethral probe in case of high fistula far from the bladder cervix and a cystostomy in cervical and urethral low fistulas. The duration of the bladder drainage were not recommended by these authors. In our series, drainage lasted 14 days for 19 patients and 21 days for 45 patients according to the transection cure was insolated or associated with urethroplasty. Ruminjo et al. [11] reported a median duration of urethral catheterism of 21 days (14 - 27). The success rate in our series is in the range of literature where it ranges from 57 to 96\% of cases [10] [12] [13] [15] [20]. For Falandry, the healing rate varies depending on the extent of the necrotic damage and can reach $100 \%$ for Group I, 75\% for Group II and 50\% for Group III [7].

This healing is sometimes obtained from the outset from the first intervention, other times at the end of complex surgery, repeated and traumatic for patient very affected psychologically as confirmed by the study made by the Wilson and Harouna et al. [2] [21]. The repeated surgery rate in our series (33\%) was higher than that of Guirassy et al. [8] in the same service in 1995 reporting $20 \%$. Indeed, each failure results in a sclerosis that is added to the primitive sclerosis, with less irrigated tissues [14] [19].

Urine continence failure after the fistula closes was $9 \%$ in our series against $10.4 \%$ for Sludge [22], 11\% for Arrowsmith [23], 18.9\% for Ruminjo [11] and $23.1 \%$ for Kimassoum et al. [24]. In any case where urethroplasty used vaginal tissue (vaginal flap urethroplasty) we observed bad results. The high failure rate in our $33 \%$ series could be related to the destruction of the urethra (type II and III of transections) and the sclerotic state of the vagina. Overall, about $15 \%$ of vaginal fistulas are incurable, despite the use of various surgical techniques. These cases are results either from enterocyctoplasty enlargement or replacement from urinary derivatives [12]. Palliatives interventions that seem best suited to our context are continent urinary derivatives such as continent vesicostomy or the ileoecoecale bladder continent of Benchekroun [10] [12].

\section{Conclusion}

The vesico-vaginal fistula transection type is severe obstetric fistulas as a result of their extention, associated lesions and the continence system damage. They are secondary to prolonged hard labour during delivery among young parturients. The preferential surgical approach was vaginal. Fistulorraphy with a con- 
ception of a new cervix and cervico-urethral anastomosis was the basic technique that can be associated with urethroplasty by bladder or vaginal flap. The poor results were related to the type of transection (Type III and IV), the sclerotic state of the vagina, the number of previous cures and to the vagynal flap uretrhoplasty. Adequate support of delivery favours the reduction of the vesico-vaginal fistula.

\section{Conflicts of Interest}

The authors declare no conflicts of interest regarding the publication of this paper.

\section{References}

[1] Rochat, C.-H., Gueye, S.M., Colas, J.-M., Dumurgier, C., Falandry, L., Blanchot, J., Eglin, G. and Tebeu, P.-M. (2011) Vesicovaginal Fistulas and Obstetrical Fistulas-EMC Surgical Techniques. Urology, 41-175.

[2] Wilson, S.M., Sikkema, K.J., Watt, M.H., Masenga, G.G. and Mosha, M.V. (2016) Psychological Symptoms and Social Functioning Following Repair of Obstetric Fistula in a Low-Income Setting. Maternal and Child Health Journal, 20, 941-945. https://doi.org/10.1007/s10995-016-1950-z

[3] Anoukoum, T., Attipou, K., Agodakoussemou, L.K., Akpadza, K. and Aayite, E.A. (2010) Epidemiological, Etiological and Therapeutic Aspects of Obstetric Fistula in Togo. Progrès en Urologie, 20, 71-76. https://doi.org/10.1016/j.purol.2009.08.038

[4] Ndiaye, P., Amoul Kini, G., Adama, F., Idrissa, A. and Tal-Dia, A. (2009) Urogenital Fistula of Obstetric Origin (Fugo): Cost of Care at the Niamey National Hospital (Niger). Revue d’ épidémiologie et de Santé Publique, 57, 374-379. https://doi.org/10.1016/j.respe.2009.04.010

[5] Aristide Kabore, F., Kambou, T., Ouattara, A., Zango, B., Yameogo, C., Kirakoya, B., et al. (2014) Epidemiological, Etiological and Psychosocial Aspects of Urogenital Fistula in a Cohort of 170 Consecutive Patients, Taken Care of in Three Centers of Burkina Faso from 2010 to 2012. Progrès en Urologie, 24, 526-532. https://doi.org/10.1016/j.purol.2014.03.001

[6] Waaldijk, K. and Armiya'u, Y.D. (1993) The Obstetric Fistula: A Major Public Health Problem Still Unsolved. International Urogynecology Journal, 4, 126-128. https://doi.org/10.1007/BF00376428

[7] Falandry, L. (1992) Treatment of Post-Partum Uro-Genital Fistulas in Africa. 261 Cases Observed in Ten Years. Progrès en Urologie, 2, 861-873.

[8] Guirassy, S., Diallo, I.S., Bah, I., Diallo, M.B., Sow, K.B., Diabate, I., et al. (1995) Epidemiological and Therapeutic Aspects of Uro-Genital Fistulas in Guinea. Progrès en Urologie, 5, 684-689.

[9] Diallo, A.B., Sy, T., Bah, M.D., Diallo, T.M.O., Barry, M.S., Bah, I., Barry, T.H., Blanchot, J., Rochat, C.-H. and Diallo, M.B. (2016) Obstetric Vesico-Vaginal Fistula in Guinea: Analysis of Data from 3 Sites of Management of the NGO Engender Health. Progrès en Urologie, 26, 145-151.

https://doi.org/10.1016/j.purol.2016.01.006

[10] Benchekroun, A., El Alj, H.A, El Sayegh, H., Lachkar, A., Nouini, Y., Benslimane, L., Belahnech, Z., Marzouk, M. and Faik, M. (2003) Vesico-Vaginal Fistula: About 1050 Cases. Annales d Urologie, 37, 194-9198. 
https://doi.org/10.1016/S0003-4401(03)00053-6

[11] Ruminjo, J.K., Frajzyngier, V., Abdullahi, M.B., Asiimwe, F., Barry, T.H., Bello, A., Danladi, D., et al. (2014) Clinical Procedures and Practices Used in the Perioperative Treatment of Female Genital Fistula during a Prospective Cohort Study. BMC Pregnancy and Childbirth, 14, Article No. 220.

http://www.biomedcentral.com/1471-2393/14/220

https://doi.org/10.1186/1471-2393-14-220

[12] Frajzyngier, V., Ruminjo, J., Asiimwe, F., Barry, T., Bello, A., Danladi, D., Ganda, S., et al. (2012) Factors Influencing Choice of Surgical Route of Repair of Genitourinary Fistula, and the Influence of Route of Repair on Surgical Outcomes: Findings from a Prospective Cohort Study. BJOG, 119, 1344-1353.

https://doi.org/10.1111/j.1471-0528.2012.03461.x

[13] Chelli, D., Boudaya, F., Hammedi, N., Ines, N., Bouchoucha, S., Chibani, M., Ben Zineb, N., FalfouL, A., Chelli, H. and Channoufi, M.B. (2010) Vesico-Vaginal Fistulae of Obstetric Origin. About 131 Cases. La Tunisie Medicale, 88, 414-419.

[14] Gueye, S.M., Diagne, B.A. and Mensah, A. (1992) Les Fistules Vésico-Vaginales: Etiopathogenic and Therapeutic Aspects in Senegal. Les Médecine d Afrique Noire, 39, 8-9.

[15] Moudouni, S., Nouri, M., Koutani, A., Ibn Attya, A., Hachimi, M. and Lakrissa, A. (2001) Obstetric Vesicovaginal Fistulas. About 114 Cases. Progrès en Urologie, 11, 103-108.

[16] Tazi, K., EL Fassi, J., Karmouni, T., Koutani, A., Ibn Attya, A.A., Hachimi, M. and Lakrissa, A. (2001) Complex Vesicovaginal Fistulas. About 55 Cases. Annales d Urologie, 35, 339-343. https://doi.org/10.1016/S0003-4401(01)00056-0

[17] Bodner-Adler, B., Hanzal, E., Pablik, E., Koelbl, H. and Bodner, K. (2017) Management of Vesicovaginal Fistulas (VVFs) in Women Following Benign Gynaecologic Surgery: A Systematic Review and Meta-Analysis. PLoS ONE, 12, e0171554. https://doi.org/10.1371/journal.pone.0171554

[18] Kambou, T., Zango, B., Ouattara, T.A., Diao, B., and Sanou, D. (2006) Update on the Management of Urogenital Fistulas Souro Sanou University Hospital in Bobo Dioulasso: Study 57 Cases Operated in 2 Years. Médecine d'Afrique Noire, 53, 665-673.

[19] Schlienger, G., Laroche, J., Karsenty, G., Bertrand, S., Dulac, J.P., Fournier, R. and Savoie, P.H. (2012) Obstetric Vesico-Vaginal Fistulas for an Isolated Surgeon in Africa. Médecine et Santé Tropicales, 22, 126-130.

https://doi.org/10.1684/mst.2012.0060

[20] Delamou, A., Diallo, M., Beavogui, A.H., Delvaux, T., Millimono, S., Kourouma, M., Beattie, K., Barone, M., et al. (2015) Outcomes of Fistula Repair in Guinea. Tropical Medicine and International Health, 20, 813-819. https://doi.org/10.1111/tmi.12489

[21] Harouna, Y.D., Seibou, A., Maikano, S., Djambeidou, J., Sangaré, A., Bilane, S.S. and Abdou, H.M. (2001) Obstetric Vesico-Vaginal Fistula: Investigation of 52 Women Admitted to the Village of Fistula. Les Médecine d Afrique Noire, 48, 55-59.

[22] Sombie, I., Kambou, T., Conombo, S.G., Sankara, O., Ouedraogo, L., Zoungrana, T., Hounton, S. and Meda, N. (2007) A Retrospective Review of Obstetric Urogenital Fistula from 2001 to 2003 in Burkina Faso. Médecine Tropicale, 67, 48-52.

[23] Arrowsmith, S.D., Ruminjo, J. and Landry, E.G. (2010) Current Practices in Treatment of Female Genital Fistula: A Cross Sectional Study. BMC Pregnancy and Childbirth, 10, Article No. 73. http://www.biomedcentral.com/1471-2393/10/73 https://doi.org/10.1186/1471-2393-10-73 
[24] Kimassoum, R., Franklin, D.S., Arya, Z.A.T. and Kaboro, M. (2016) Evaluation of the Treatment of Urinary Incontinence after Obstetric Fistula Cure. Uro' Andro, 1, 242-246. 